\title{
Protective effect of collateral vessels during coronary angioplasty
}

\author{
MICHAEL S NORELL, JOHN P LYONS, JOHN E GARDENER, CLIVE A LAYTON, \\ RAPHAEL BALCON
}

From the Cardiac Department, London Chest Hospital, London

SUMMARY To assess the potential protective role of collateral vessels 27 patients undergoing angioplasty of the left anterior descending coronary artery were studied by intravenous digital subtraction left ventriculography. Fifteen patients had no collateral vessels (group 1) and 12 had some degree of collateral supply (group 2). During balloon inflation ST segment elevation in group $1(4.9 \mathrm{~mm})$ was significantly greater than that in group $2(0.9 \mathrm{~mm})$. Similarly the reduction in left ventricular ejection fraction was significantly greater in group $1(24 \%)$ than in group $2(12 \%)$. Both the size of ST segment elevation and the fall in ejection fraction correlated inversely with the extent of the collateral supply ( $r=-0.680$ and $r=-0.446$ respectively). During balloon occlusion of the anterior descending coronary artery the percentage shortening of the anterior and apical segments fell in both groups but apical shortening fell to a lesser extent in group 2 . An additional reduction in anterobasal contraction was confined to group 1.

Electrocardiographic and ventriculographic manifestations of ischaemia produced by balloon inflation during angioplasty are less pronounced when collateral vessels are present. This suggests that the collateral circulation can protect myocardium at risk of ischaemia after coronary occlusion.

The extent to which collateral vessels can protect the myocardium during coronary occlusion is not known. Many earlier studies were retrospective and attempted to relate the degree of left ventricular damage after thrombotic coronary occlusion to the subsequent arteriographic assessment of collateral circulation. ${ }^{12}$ Coronary angioplasty, by producing transient, controlled coronary occlusion has allowed a prospective examination of both the angiographic development and the functional role of the collateral circulation..$^{3-5}$ We showed that global and regional left ventricular performance can be assessed during coronary angioplasty with intravenous digital subtraction ventriculography. ${ }^{6} \mathrm{We}$ used this technique to examine the degree to which collateral vessels protect the myocardium during transient coronary occlusion produced by balloon inflation.

\section{Patients and methods}

We studied 27 patients ( 22 men and five women,

Requests for reprints to Dr Michael S Norell, Cardiac Department, Harefield Hospital, Harefield, Middlesex UB9 6JH.

Accepted for publication 11 April 1989 mean age 52). They belonged to a group described in a feasibility study that examined the effect of coronary angioplasty on left ventricular function. ${ }^{6}$ They all had limiting angina despite optimum medical treatment. At the time of the study 23 patients were taking a $\beta$ adrenergic blocking agent, 25 were taking a calcium antagonist, and 21 were taking nitrates. Seventeen patients were in class 3 of the Canadian Cardiovascular Society while the remaining 10 patients were in class 4 .

All patients had single vessel coronary disease defined as at least a $70 \%$ reduction in luminal diameter affecting only the left anterior descending artery proximal to its first diagonal branch. The estimated severity of the lesions treated by angioplasty ranged from $70 \%$ to $99 \%$ (mean $89 \%$ ). In all cases the stenoses allowed anterograde flow of contrast. Left ventriculography showed normal contraction in all patients, the mean ejection fraction being $75 \%$.

COLLATERAL ASSESSMENT

Coronary arteriograms performed before the angioplasty procedure were reviewed by two observers to assess any collateral circulation. As is routine in our laboratory, selective arteriograms were performed in 
multiple projections and we used 3-5 $\mathrm{ml}$ of contrast injected by hand over 1-3 seconds. Cinerecording was continued after each injection until it was apparent that there was no further vessel opacification. Any collateral circulation was then measured by a method ${ }^{4}$ that grades collaterals according to the extent to which the epicardial arterial segment distal to the target stenosis is retrogradely opacified: no collateral vessels visible, 0 ; collateral vessels visible, $1 ;<50 \%$ opacification of distal segment, $2 ;>50 \%$ opacification of distal segment, 3.

\section{ANGIOPLASTY PROCEDURE}

Patients received premedication with an oral nitrate, calcium antagonist, and dipyridamole an hour before the angioplasty procedure. Angioplasty was performed via the femoral approach with $2.5 \mathrm{~mm}$ or $3 \mathrm{~mm}$ balloon catheters and steerable guide wires. Patients underwent 3-7 balloon inflations each for 20 to 60 seconds at inflation pressures ranging from 5-10 atm (1 atm $\bumpeq 101 \mathrm{kPa})$. The electrocardiogram was allowed to return to baseline before subsequent inflations.

\section{ELECTROCARDIOGRAPHY}

A 12 lead electrocardiogram at a paper speed of $25 \mathrm{~mm} / \mathrm{s}$ was monitored throughout the angioplasty procedure. The time of balloon inflation and deflation was marked, as was the onset of digital ventriculography. Any change in ST segment ( $>1 \mathrm{~mm}$ ) was measured with a graticule $80 \mathrm{~ms}$ after the J point and the maximum change in any lead recorded.

\section{DIGITAL VENTRICULOGRAPHY}

Digital subtraction left ventriculography after contrast injection into the right atrium was performed before and during ( $>20 \mathrm{~s}$ ) either the third (21 patients) or fourth (six patients) balloon inflation, according to a previously described method. ${ }^{6}$ We injected $40 \mathrm{ml}$ of non-ionic contrast medium (iohexol; Omnipaque $350 \mathrm{mg}$ iodine/ml, Nycomed) at $17 \mathrm{ml} / \mathrm{s}$ through a 5 French pigtail catheter (Superflow, Cordis) during held inspiration. Ventriculograms were acquired at 12.5 frames/s on to a $256 \times 256$ pixel matrix with a Siemens Digitron connected on line to a Siemens Elema Angioskop D imaging system. End diastolic and subsequent end systolic frames were selected, excluding extrasystoles, and their outline was manually digitised by an observer blinded to the patient's collateral circulation. An area-length method was used to calculate left vẹntricular volumes ${ }^{7}$ and hence ejection fraction. To assess regional left ventricular wall motion we used a method that calculates the percentage systolic shortening of radii from the end systolic centre of gravity to the end diastolic perimeter. ${ }^{8}$ This was modified so that the results could be expressed as percentage shortening for each of five left ventricular regions: anterobasal, anterior, apical, inferior, inferobasal. ${ }^{6}$

\section{STATISTICAL ANALYSIS}

Patients were divided into two groups depending on whether or not any collateral supply could be seen angiographically. Statistical tests included paired or unpaired Student's $t$ test as appropriate. To relate electrocardiographic or ventriculographic changes to the collateral grade, Spearman's rank correlation was used.

This study was approved by the ethics committee of the National Heart and Chest Hospitals and all patients gave written informed consent.

\section{Results}

\section{ASSESSMENT OF COLLATERALS}

Fifteen of the 27 patients studied had no angiographically demonstrable collateral vessels (group 1, collateral grade $=0$ ) while the remaining 12 patients had some degree of collateral supply (group 2, mean collateral grade $=1 \cdot 7$ ). The severity of coronary obstruction was greater in group 2 than in group 1 $(94 \% v 86 \%, \mathrm{p}<0.05)$.

\section{ELECTROCARDIOGRAPHY}

During balloon inflation in the left anterior descending coronary artery the degree of ST elevation in group 1 (mean $=4.9 \mathrm{~mm}$, range $0-9 \mathrm{~mm}$ ) was greater than that in group 2 (mean $=0.9 \mathrm{~mm}$, range $0-5 \mathrm{~mm}, \mathrm{p}<0.001)$. There was an inverse correlation between the magnitude of ST segment elevation and the collateral grade $(r=-0.680, p<0.001$, fig 1).

\section{GLOBAL LEFT VENTRICULAR PERFORMANCE}

Before angioplasty the left ventricular ejection fraction was similar in the two groups (group $174 \%$, group $278 \%$, NS). During balloon inflation ejection fraction decreased to $50 \%$ in group $1(\mathrm{p}<0.001)$ but only to $66 \%$ in group 2 (p $<0.001)$. This fall was significantly larger in group 1 than in group $2(24 \% v$ $12 \%, \mathrm{p}<0.01)$.

There was an inverse correlation between the fall in left ventricular ejection fraction during balloon inflation and the extent of the collateral supply $(r=-0.446, p<0.01$, fig 2).

\section{REGIONAL LEFT VENTRICULAR}

PERFORMANCE (TABLE 1)

Before angioplasty there were no significant differences between the two groups in left ventricular regional shortening. During balloon inflation in the anterior descending artery anterior and apical 


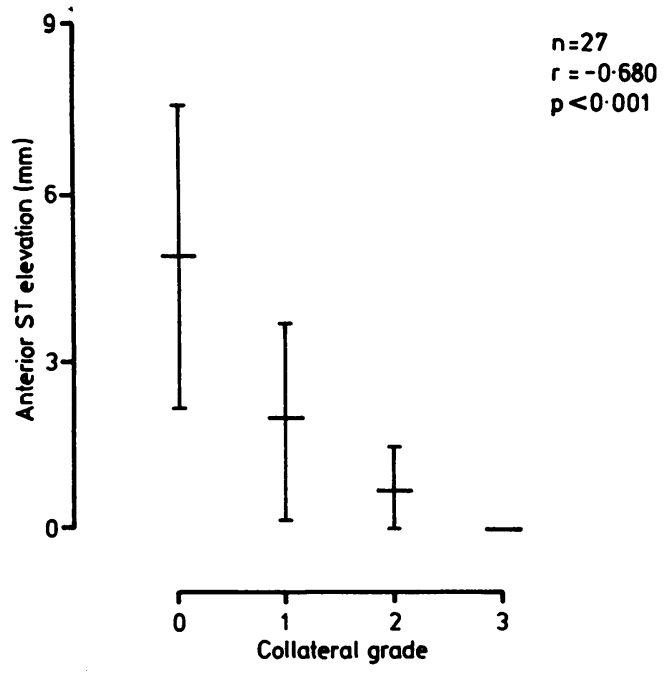

Fig 1 Relation between the extent of collateral supply (collateral grade) and anterior $S T$ segment elevation (mean (SD)) during balloon inflation in the left anterior descending artery.

regional shortening decreased in both groups (group $138 \%$ to $12 \%, \mathrm{p}<0.001 ; 51 \%$ to $11 \%, \mathrm{p}<0.001$ respectively and group $242 \%$ to $19 \%, \mathrm{p}<0.001$; $55 \%$ to $26 \%, p<0.001$ respectively). Anterobasal shortening decreased significantly only in group 1 $(37 \%$ to $24 \%, \mathrm{p}<0.01)$ and not in group $2(38 \%$ to $33 \%$, NS). Apical shortening during balloon inflation was also better preserved in group $2(26 \%)$ than in group $1(11 \%, p<0.05)$.

Shortening in the inferior region during angioplasty did not change significantly in either group (group $148 \%$ to $43 \%$, NS; group $248 \%$ to $53 \%$, NS), but inferobasal contraction was equally enhanced in both groups (group $18 \%$ to $23 \%, \mathrm{p}<0.01$; group $25 \%$ to $27 \%, p<0.01$ ).

The reduction in anterobasal, anterior, and apical regional shortening during balloon occlusion of the anterior descending coronary artery tended to be larger in those patients without collateral vessels (group 1) than in group 2, but these differences were not significant (table 2).
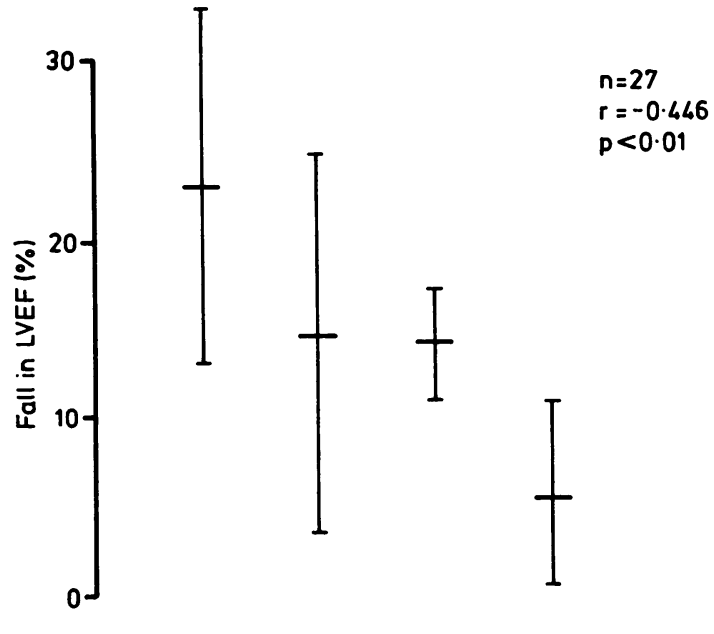

Fig 2 Relation between the extent of collateral supply (collateral grade) and the reduction in left ventricular ejection fraction (mean (SD)) (LVEF) during balloon inflation in the left anterior descending artery.

Table 2 Reduction in left ventricular segmental shortening $(\%$, mean $(S D))$ during angioplasty of the anterior descending coronary artery in patients without (group 1) or with (group 2) collateral vessels

\begin{tabular}{lcrl}
\hline Left ventricular segment & $\begin{array}{l}\text { Group 1 } \\
(n=15)\end{array}$ & $\begin{array}{c}\text { Group 2 } \\
(n=12)\end{array}$ & $p$ \\
\hline Anterobasal & $13(15)$ & $5(12)$ & NS \\
Anterior & $26(13)$ & $23(17)$ & NS \\
Apical & $40(18)$ & $29(20)$ & NS \\
Inferior & $5(18)$ & $+5(10)$ & NS \\
Inferobasal & $+15(18)$ & $+22(23)$ & NS \\
\hline
\end{tabular}

Positive $(+)$ value indicates an increase in segmental shortening.

\section{Discussion}

Previous studies of the potential protective role of collateral vessels have related the degree of left ventricular dysfunction after thrombotic coronary

Table 1 Comparison of left ventricular regional shortening (\%, mean (SD)) before and during angioplasty of the anterior descending coronary artery in patients without (group $1, n=15$ ) or with (group $2, n=12$ ) collateral vessels

\begin{tabular}{|c|c|c|c|c|c|c|}
\hline \multirow[b]{2}{*}{$L V$ segment } & \multicolumn{3}{|c|}{ Before PTCA } & \multicolumn{3}{|c|}{ During PTCA } \\
\hline & Group 1 & Group 2 & $p$ & Group 1 & Group 2 & $p$ \\
\hline $\begin{array}{l}\text { Anterobasal } \\
\text { Anterior } \\
\text { Apical } \\
\text { Inferior } \\
\text { Inferobasal }\end{array}$ & $\begin{array}{l}37(9) \\
38(9) \\
51(8) \\
48(13) \\
8(11)\end{array}$ & $\begin{array}{l}38(11) \\
42(11) \\
55(12) \\
48(15) \\
5(14)\end{array}$ & $\begin{array}{l}\text { NS } \\
\text { NS } \\
\text { NS } \\
\text { NS } \\
\text { NS }\end{array}$ & $\begin{array}{l}24(13) \\
12(11) \\
11(14) \\
43(14) \\
23(17)\end{array}$ & $\begin{array}{l}33(17) \\
19(24) \\
26(22) \\
53(13) \\
27(23)\end{array}$ & $\begin{array}{c}\text { NS } \\
\text { NS } \\
<0.05 \\
\text { NS } \\
\text { NS }\end{array}$ \\
\hline
\end{tabular}

LV, left ventricular; PTCA, percutaneous transluminal coronary angioplasty. 
occlusion to the extent of the collateral circulation that was later apparent. Although some found that left ventricular damage was reduced when there was an extensive collateral system ${ }^{12}$ others did not. ${ }^{9}$ Such retrospective studies have to be viewed with caution because the state of the collateral circulation at the time of coronary occlusion is unknown. Coronary angioplasty, however, allows further assessment of the development and functional role of these vessels. Collateral vessels that were not apparent before angioplasty were seen during balloon inflation, ${ }^{34}$ and those present before the procedure disappeared after successful angioplasty. ${ }^{10}$ When the haemodynamic contribution of collaterals to the coronary circulation was examined during angioplasty, ${ }^{11}$ the pressure distal to an inflated angioplasty balloon was shown to relate to the extent of the collateral supply shown by angiography.

We assessed the function of the collateral circulation and showed that the manifestations of myocardial ischaemia during balloon occlusion of the anterior descending artery were reduced when collateral vessels filled the distal arterial segment. Furthermore, we showed that the degree of ischaemia produced during balloon inflation correlated with the extent of the collateral supply. These findings accord with those of others. ${ }^{5}$ Cohen and Rentrop examined the occurrence of anginal pain, together with the degree of ST segment elevation and echocardiographic evidence of left ventricular dysfunction during balloon inflation. They related these findings to the collateral supply apparent angiographically during balloon occlusion and also showed that these indices of myocardial ischaemia were reduced in the presence of collateral vessels.

The present study differs from that of Cohen and Rentrop. Although we used a similar system to grade the collateral supply, ${ }^{4}$ we assessed the collateral circulation before, rather than during, balloon inflation. Because the ability to demonstrate collateral vessels angiographically is dependent on the degree of proximal arterial obstruction, ${ }^{29}$ we may have underestimated the collateral state before balloon occlusion. However, other workers have shown that although the collateral filling of a distal arterial segment may increase abruptly after balloon occlusion, the protective effect of such apparently increased flow is variable. ${ }^{3}$

We found that even when there was an extensive collateral supply ventriculographic abnormalities still occurred during balloon inflation. This also accords with the finding of others who noted the development of angina, ST segment elevation, and left ventricular dysfunction during balloon occlusion despite the complete opacification of the index artery by collateral vessels. ${ }^{5}$ This suggests that even an abundant collateral supply may be inadequate to protect completely a potentially ischaemic myocardium. Previous studies also showed that collateral vessels do not necessarily reduce the extent of exercise induced myocardial ischaemia ${ }^{21213}$ or the subsequent incidence of cardiac events. ${ }^{14}$ Furthermore, because all the patients in the present study were limited by angina before angioplasty, the finding that their collateral circulation was not sufficient is not unexpected.

The extent of a collateral circulation is usually assessed with selective coronary arteriography. This method itself may have limitations because several factors can influence the appearance of collateral vessels after selective injection of contrast into a coronary artery. Because the opacification of collateral vessels depends on a pressure gradient across the coronary beds, the pressure used for contrast injection and the degree of proximal obstruction are especially relevant in determining the appearance of collaterals. The presence of vasodilator drugs and the resolution of the angiographic equipment are also important.

We made no attempt to standardise the pressure and flow rate of selective coronary injections in our patients; we used our routine technique for diagnostic coronary angiography. All our patients were given vasodilators (a nitrate and a calcium antagonist) before angioplasty to ameliorate any ischaemia and reduce any tendency to coronary spasm during the procedure. The specific effect of such drugs on collateral vessels is unclear. ${ }^{1516}$ Thus although an angiographic assessment of collateral vessels may have limitations, it does indicate the extent of the collateral circulation and this is borne out by the results of our study.

Coronary angioplasty, by producing reversible, controlled coronary occlusion, allowed a prospective study of the function of collateral vessels. The electrocardiographic and ventriculographic manifestations of ischaemia during balloon inflation were less pronounced in patients in whom a collateral circulation was seen. This supports the view that such vessels can protect myocardium at risk of ischaemia after coronary occlusion.

MSN was supported by the British Heart Foundation.

\section{References}

1 Fulton WFM. Anastomotic enlargement and ischaemic myocardial damage. Br Heart J 1964;26:1-15.

2 Freedman SB, Dunn RF, Bernstein L, Morris J, Kelly DT. Influence of coronary collateral blood flow on the development of exertional ischaemia and $Q$ wave 
infarction in patients with severe single vessel disease. Circulation 1985;71:681-6.

3 Hill JA, Feldman RL, MacDonald RG, Pepine CJ. Coronary artery collateral visualisation during acute coronary occlusion. Am J Cardiol 1985;55:1216-8.

4 Rentrop KP, Cohen M, Blanke H, Phillips RA. Changes in collateral channel filling immediately after controlled coronary artery occlusion by an angioplasty balloon in human subjects. $\mathrm{J} \mathrm{Am}$ Coll Cardiol 1985;5:587-92.

5 Cohen M, Rentrop KP. Limitation of myocardial ischaemia by collateral circulation during sudden controlled coronary artery occlusion in human subjects: a prospective study. Circulation 1986;74:469-76.

6 Norell MS, Lyons JP, Gershlick AH, et al. Assessment of left ventricular performance during percutaneous transluminal coronary angioplasty: a study by intravenous digital subtraction ventriculography. $\mathrm{Br}$ Heart $J$ 1988;59:419-28.

7 Sandler H, Dodge HT. The use of single plane angiocardiograms for the calculation of left ventricular volume in man. Am Heart $J$ 1968;75:325-34.

8 Rickards A, Seabra-Gomes R, Thurston P. The assessment of regional abnormalities of the left ventricle by angiography. Eur J Cardiol 1977;5:167-82.

9 Elayda MA, Mathur VS, Hall RJ, et al. Collateral circulation in coronary artery disease. Am J Cardiol 1985;55:58-60.
10 Legrand V, Aueron FM, Bates ER, et al. Reversibility of coronary collaterals and alteration in regional coronary flow reserve after successful angioplasty. Am J Cardiol 1984;54:453-4.

11 Probst P, Zangl W, Pachinger O. Relation of coronary arterial occlusion pressure during PTCA to presence of collaterals. Am J Cardiol 1985;55:1264-9.

12 Tubau JF, Chaitman BR, Bourassa WG, Lesperance J, Dupras G. Importance of coronary collateral circulation in interpreting exercise test results. $\mathrm{Am} \mathrm{J} \mathrm{Cardiol}$ 1981;47:27-32.

13 Kolibash AJ, Bush CA, Wepsic RA, et al. Coronary collateral vessels: spectrum of physiologic capabilities with respect to providing rest and stress myocardial perfusion, maintenance of left ventricular function and protection against infarction. Am J Cardiol 1982; 50:230-8.

14 Nestico PF, Hakki AH, Meissner MD, et al. Effect of collateral vessels on prognosis in patients with one vessel coronary artery disease. $\mathrm{J} \mathrm{Am} \mathrm{Coll} \mathrm{Cardiol}$ 1985;6:1257-63.

15 Bass TA, O'Brien JT, Conetta DA, Perryman RA, Miller AB. Dynamic appearance of collaterals during transluminal coronary angioplasty [Abstract]. Circulation 1984;70(suppl II):36.

16 Weintraub WS, Hattori S, Akizuki S, et al. Influence of nifedipine on collateral blood flow during acute ischaemia in the dog. J Am Coll Cardiol 1984;3:33440. 